\title{
Deducing Markups from Stockout Behavior
}

\author{
Mark Bils \\ University of Rochester and NBER
}

March 2016

\begin{abstract}
Stockouts bear an inverse relation to the price markup in models with a stockout constraint on sales because stockouts cost the seller the markup of price over marginal cost. I examine stockouts in micro CPI data, for goods comprising more than a quarter of consumer expenditures, to deduce the level and cyclicality of markups for 1988 to 2009. The predictable increase in stockouts, as price declines, over durables' product life implies markups on the order of 15 percent. For much of the sample period stockouts were acyclical, suggesting markups were acyclical. But for the latter part of the sample, including the Great Recession, stockouts are procyclical consistent with countercylical markups.
\end{abstract}

*For various suggestions and help, I want to thank David Johnson, James Kahn, Paul Liegey, Julio Rotemberg, and Teague Ruder. This work began while I was visiting the Bureau of Labor Statistics (BLS) under the IPA (Intergovernmental Personnel Act) agreement. Any interpretations presented are my own, and should not be associated with the BLS. The research was supported by a grant from the National Science Foundation. 
Business cycle fluctuations exhibit important procyclical movements in hours and consumption. Market-clearing business-cycle models typically generate these opposite movements in leisure and consumption through very procyclical movements in the marginal product of labor. But labor productivity is quite acyclical in the data. This makes it difficult to rationalize hours fluctuations without market features that can drive a cyclical wedge between the marginal physical product of labor and marginal rates of substitution between leisure and consumption. (Shimer, 2009, provides a thorough discussion of these issues.) This observation has helped renew interest in models with wage and/or price stickiness. Prices that are less procyclical than marginal cost can contribute to hours fluctuations by making labor's marginal revenue product more procyclical than its marginal physical product. Goodfriend and King (1997) show how sticky-price models contribute to hours fluctuations by creating countercyclical movements in price markups. Clearly purposeful movements in price markups can serve this role (e.g., Rotemberg and Woodford, 1999).

Judging the behavior of price markups over marginal cost is difficult because we do not observe the shadow price of labor (Kudlyak, 2014, Basu and House, 2015). If it is assumed that labor's marginal product varies in proportion to its average product and that the shadow price of labor is captured by average hourly wages, then fluctuations in the price markup are reflected (inversely) by fluctuations in labor's share of output. Labor's share is not particularly cyclical; so this approach implies little cyclical variation in the markup (Gali, Gertler, Lopez-Salido, 2007, Nekarda and Ramey, 2013, Karabarbounis, 2014). But this measure of the markup can be strongly biased with respect to the business cycle if labor is quasifixed or wages are smoothed by employers across fluctuations (Bils, 1987, Rotemberg and Woodford, 1999, Bils, Klenow, and Malin, 2015).

Here I exploit information on the frequency that products stock out, derived from micro data underlying the CPI, to judge the level and cyclical behavior of price markups over marginal cost. Research in inventory behavior has been motivated by related questions. This work connects most closely to that by Bils and Kahn (2000), Galeotti, Maccini, and Schiantarelli (2005), and Kryvtsov and Midrigan (2012), each of whom use inventory 
movements to identify the structure of costs and nature of business cycle shocks. Looking directly at stockout behavior has distinct advantages over studying inventories. For one, stockout information is available for many goods for which data on finished inventories are not available.

In the next section I consider the production choice for firms facing a constraint that sales cannot exceed the stock available (as in Kahn, 1987, 1992). By stocking one more good for sale, the seller gains a sale in the event that a stockout occurs. To generate a predictable increase in the probability of stocking out requires: (1) a temporary increase in marginal cost (an increase relative to discounted future marginal cost), or (2) a decrease in the markup of price over marginal cost. Thus, given data on prices and interest rates, the likelihood of a stockout is informative on the behavior of marginal cost and price markups.

I present data on temporary stockouts for 20 distinct consumer goods categories in Section 3. The estimates are derived from information in the CPI Commodities and Services Survey (CPI C\&S Survey), the monthly micro data underlying the Consumer Price Index. To calculate the CPI the BLS tracks a large set of prices of particular products at particular outlets. Only prices for products available for purchase are eligible for use in the CPI. For this reason, the CPI C\&S Survey data reveal the occurrence of a stockout.

10 of the 20 goods categories are durables, including apparel. Prices predictably decline with time on the market for these goods. I examine, in Section 4, how stockouts increase with shelf life, as price predictably declines. From that pattern I can judge the size of price markups over marginal cost for the consumer durables. Overly large markups are not consistent with the substantial increase in stockout rates observed over the product life for most durables. I estimate markups of about 15 percent on average, but over 20 percent for household appliances, electronic equipment, and women's' apparel.

My estimates are near the upper end of the range of most estimates in the literature (e.g., Morrison, 1992, Norrbin, 1993, Basu and Fernald, 1997) that are based on examining productivity patterns or estimating cost functions. They are, however, far below those of Hall 
(1988), who estimates quite large markups based on how output responds to instrumented expansions in inputs.

I examine the cyclical behavior of stockouts in Section 5. I find that stockouts were acyclical for much the sample period, but then become quite procyclical for its latter part. Most notably, the stockout rate dropped nearly a full percentage point during the Great Recession, which represents a decline of about 20 percent relative to the level of the stockout rate. This behavior of stockouts suggests that markups, after being acyclical for much of sample period, became notably procyclical during its latter, more volatile years.

My results for the earlier part of the sample run counter those of both Bils and Kahn (2000) and Kryryvtsov and Midrigan (2012), who estimate countercyclical markups based on very predictably countercyclical patterns in inventory to sales ratios. The concluding section discusses possible reasons for this. For the latter part of my sample, including the Great Recession, stockouts are procyclical, while the inventory-sales ratio remained highly countercyclical. ${ }^{1}$ So both approaches point to a countercyclical markup.

\section{Predicting Stockout Rates}

Consider the production decision for a firm producing to stock. In a pure productionsmoothing model of inventories this is a cost minimization problem--firm's produce more today only if marginal cost is below expected discounted future marginal costs. Here I follow Kahn (1986, 1992), Thurlow (1993), and others by allowing a larger stock for sale to be potentially valuable by reducing the probability of losing a sale because of a stockout.

\footnotetext{
${ }^{1}$ Bils, Klenow, and Malin (2015) discuss the behavior of inventory-sales ratios since 1988. That paper. as well as Hall (2014), also attempt to deduce cyclicality of price markups without measuring the cyclical price of labor. Bils, Klenow, and Malin, based on the behavior of hours for self-employed workers and inputs for intermediate goods, conclude that price markup have been systematically countercyclical for the last 25 years. Hall models the return to advertising, by increasing sales, as proportional to the markup. (Comparable to the benefit of avoiding stockouts here.) He interprets the strong procyclicality of advertising spending as support for a procyclical markup.
} 
The firm chooses output to maximize expected discounted profits subject to a constraint that sales cannot exceed the stock available.

$$
\max _{y_{t}} E\left(\sum_{i=0}^{\infty} \beta_{t, t+i}\left[p_{t+i} s_{t+i}-C\left(y_{t+i} ; \theta_{t}, \boldsymbol{w}_{t}\right)\right] \mid \boldsymbol{I}_{t}\right)
$$

subject to:

$$
\begin{gathered}
s_{t}=\min \left[d\left(p_{t}, \boldsymbol{z}_{t}\right), a_{t}\right] \\
a_{t}=i_{t}+y_{t}=a_{t-1}-s_{t-1}+y_{t} .
\end{gathered}
$$

An index for the firm's product is implicit. The expectation conditions on a set of variables $\boldsymbol{I}_{t}$ known when production is chosen for time $t . s_{t}$ and $p_{t}$ are respectively sales and price for $t$. All prices are relative to a numeraire good. $p_{t}$ is an additional choice variable for the seller. But, I focus on the optimizing choice for output, given the observed price. ${ }^{2} C\left(y_{t} ; \theta_{t}, \boldsymbol{w}_{t}\right)$ is the cost, in terms of numeraire good, of producing output $y_{t}$. It depends on a productivity factor, $\theta_{t}$, as well as a vector of input prices, $\boldsymbol{w}_{t}$. Here forward, I write this as $C_{t}\left(y_{t}\right) \cdot \beta_{t, t+i}$ denotes the real rate of discount for $i$ periods ahead. For instance, $\beta_{t, t+1}$, which I denote $\beta_{t}$ for convenience, equals $1 /\left(1+r_{t}\right)$, where $r_{t}$ is the real rate of interest (netting inflation in the numeraire's price) from $t$ to $t+1$. For convenience, (1) assumes an infinite horizon; but in the empirical work I allow for the possibility that a good has a distinct product life.

Stockout constraint (i) states that sales are equal to the quantity demanded for the product $d\left(p_{t}, \boldsymbol{z}_{t}\right)$, if this demand is less than the stock available, $a_{t}$; but otherwise equals $a_{t}$. In addition to price, the quantity demanded depends on a vector of random variables $z_{t}$, with at least one of these variables not contained in the information set $\boldsymbol{I}_{t}$. Constraint (ii) equates the stock available for sale to the beginning of period inventory plus the period's production. In turn, the beginning inventory reflects the unsold stock from the previous period.

\footnotetext{
${ }^{2}$ If $p_{t}$ is determined in advance of output then it is contained in the time $t$ information set. Otherwise it is excluded.
} 
I focus on the dynamic first-order condition to the problem in (1). Consider marginally increasing output for the firm in $t$, together with decreasing it in $t+1$, such as to keep the stock available in $t+1$ unaffected. Requiring this perturbation have no effect on expected profits yields

$$
\begin{gathered}
E\left(-c_{t}+\Gamma_{t} p_{t}+\left(1-\Gamma_{t}\right) \beta_{t} c_{t+1} \mid \boldsymbol{I}_{t}\right)=0 \\
\text { where } \Gamma_{t}\left(a_{t}, p_{t}, \boldsymbol{z}_{t}\right)=I\left[d\left(p_{t}, \boldsymbol{z}_{t}\right)>a_{t}\right] .
\end{gathered}
$$

$\Gamma_{t}$ is given by an indicator function, equaling one in the event the product stocks out, and zero otherwise. The expectation of $\Gamma_{t}$ is the probability of a stockout. This first-order condition has the following interpretation. By increasing the available stock for sale by one unit, at a marginal cost this period of $c_{t}$, a firm increases sales by $\Gamma_{t}$. These sales are at price $p_{t}$. To the extent the increase in stock available does not increase sales, it does increase the inventory carried forward to $t+1$. This extra inventory can displace a unit of production in $t+1$, saving its marginal cost $c_{t+1}$. This subsequent savings is discounted by $\beta_{t}$.

Rearranging yields

$$
E\left(\left[\Gamma_{t} m_{t}+1\right] \frac{\beta_{t} c_{t+1}}{c_{t}} \mid \boldsymbol{I}_{t}\right)=1
$$

where $m_{t}=\left(p_{t}-\beta_{t} c_{t+1}\right) /\left(\beta_{t} c_{t+1}\right) . m_{t}$ is the percent markup of price in $t$ over discounted marginal cost in $t+1$. I refer to this as the markup because $\beta_{t} c_{t+1}$ is the opportunity cost of selling a unit at date $t$. The term $\beta_{t} c_{t+1} / c_{t}$ reflects the growth rate of real marginal cost relative to a real interest rate. ${ }^{3}$

To predict an increase in stockouts requires either a predictable transient increase in marginal cost or predictable drop in the markup. A transitory increase in marginal cost, by raising the costs of accumulating inventory, makes it more costly to avoid stockouts. A lower markup reduces the benefit from selling the good, reducing firms' incentive to hold

\footnotetext{
${ }^{3} \beta_{t} c_{t+1} / c_{t}$ can be viewed equivalently as $1 /\left(1+r_{t}^{m c}\right)$, where $r_{t}^{m c}$ is a real interest rate based on comparing a nominal interest rate to the rate of inflation in nominal marginal cost.
} 
inventories to avoid stockouts. Thus predictable movements in stockouts provide information on the behavior of marginal cost and price markups.

In Bils and Kahn (2000) we relate the behavior of marginal cost and markups to predictable movements in inventory to sales ratios. We show that finished-goods inventories fail to move cyclically with expected sales, even though cross-sectional and low-frequency time-series data indicate that firms choose inventories to be proportional to sales. We find that important countercyclical movements in price markups over marginal cost are needed to explain this pattern. The information on stockouts from the CPI C\&S Survey allows me to avoid assuming a specific functional form for how inventories affect sales, as was necessary in that work, or for how demand shocks affect sales, as required in Kahn $(1987,1992)$. Implications drawn from stockout behavior, as opposed to those based on inventory-sales ratios, are also more robust to assumptions on the technology for inventory holding, such as the importance of overhead inventories.

There are several assumptions implicit in (2) that should be highlighted. The analysis assumes that any demand not satisfied during $t$ is lost to the firm. This is a natural assumption for nondurable goods. For durable goods this is less clear. For durables it is assumed that, in the event of a particular product stocking out, the consumer substitutes a competing brand or product. ${ }^{4}$ (Studies by Emmelhainz et al., 1991, Fitzisimons, 2000, and Campo et al, 2003, report that the most common behavior of consumers faced with a stockout is to substitute a competing brand.) To the extent firms can recoup lost sales at a future date, the treatment in (2) overstates the cost of a stockout. Related to this, the data on stockouts I employ relate to a good being unavailable at a particular retail outlet. It is possible that, facing a stockout at one outlet, a consumer could purchase at another outlet. In this instance the data observation of a temporary stockout at an outlet does not correspond directly to the

\footnotetext{
${ }^{4}$ This might include the possibility that the consumer places an order for the product for future delivery from this or a competing seller. To the extent these orders are placed with the stocked-out store, equation (2) requires the "production to order" market be competitive. For instance, I might be willing to pay a markup to gain immediate possession of a book or exercise bike from a store. But, if the good is not available, that store will have to compete against more perfect substitutes (for instance, purchases over the Internet) in the market for future delivery. (Related, Kahn, 1987, discusses the impact of allowing rainchecks.)
} 
realization of $\Gamma_{t}=1$ (a stockout) in equation (2). I return to these issues when interpreting the empirical work. For the most part, the empirical work can be generalized to allow for a fraction of stockouts to be recouped by the firm.

The discussion of first-order condition (2) above frames the markup relative to marginal cost of production. This implicitly aggregates the producer and retailer's decisions. That is, I am assuming the production decision is joint wealth maximizing for the producer and retailer. Alternatively, if there are important distortions in the market between producers and retailers, then it becomes necessary to take a stand on who determines the inventory available for sale, producers or retailers. Producers do determine the total stock of inventory by their choice of how much to produce. I am assuming producers then optimally allocate the product across retail outlets. But, if retailers have considerable influence on the inventory received, then the behavior could partly reflect distortions in the transfer pricing between producers and retailers.

The first-order condition assumes strictly positive production of the good at time $t+1$. In the CPI data a number of goods become permanently unavailable at a retailer, typically replaced by newer product models. For this reason, in the empirical work I focus on stockout rates based only on observations that clearly predate the good becoming permanently (or seasonally) unavailable.

Finally, it is useful to add an assumption that the random variable $\left[d\left(p_{t}, \boldsymbol{z}_{t}\right)-a_{t}\right]$ has a distribution that is continuous at the value of zero. The CPI C\&S provides information on whether a product has a positive inventory. Observing no inventory in stock corresponds to the incidence of a stockout if there is a negligible probability that demand exactly equals stock available.

If we assume the two variables $\left(\Gamma_{t} m_{t}+1\right)$ and $\frac{\beta_{t} c_{t+1}}{c_{t}}$ in first-order condition (2) are conditionally distributed jointly lognormal, then (2) can be written as

$$
E\left(\Gamma_{t} m_{t}+\ln \left(\frac{\beta_{t} c_{t+1}}{c_{t}}\right) \mid \boldsymbol{I}_{t}\right)+\kappa \approx 0
$$

$\kappa$ reflects variance and covariance terms for the two random variables that are assumed 
constant. (See, for instance, Hansen and Singleton, 1982.) The approximation reflects replacing $\ln \left(\Gamma_{t} m_{t}+1\right)$ with $\Gamma_{t} m_{t}$. In steady state the ratio $\Gamma m$ equals a short-term real interest rate plus perhaps short-term storage costs, putting it on the order of 0.01 . So the approximation error should be very small. Much of the empirical work employs this form for the first-order condition.

The first-order equation links predictable variations in stockouts to variations in price markups and to intertemporal movements in costs. I use this equation in Section 5 to test hypotheses about the cyclical behavior of markups. Sbordone (2001), Gali, et al. (2007), and Karabarbounis (2014) attribute little importance to cyclical movement in markups. If one assumes a constant markup in pricing this not only eliminates variations in the markup as an explanation for changing stockout rates, but also implies that intertemporal variations in marginal cost can be measured by intertemporal price movements. Substituting in equation (2) for a constant markup of price over the expectation of $\beta_{t} c_{t+1}$ yields

$$
E\left(\left[\Gamma_{t} m+1\right] \frac{\beta_{t-1} p_{t}}{p_{t-1}} \mid \boldsymbol{I}_{t-1}\right)=1 .
$$

Thus a predictable increase in stockouts requires an opposite decrease in the good's rate of price inflation relative to the rate of interest, or equivalently, an increase in the good's own real rate of interest. Note that equation (4) does not depend on any particular specification of production or cost functions. ${ }^{5}$

By contrast suppose there are no predictable intertemporal fluctuations in (discounted) marginal cost, beyond that of an upward or downward trend in costs. This implies a constant expectation for $\Gamma_{t} m_{t}$. I use this prediction in Section 4 to gauge the magnitude of markups. Prices of consumer durables fall notably over the product life, even well in advance of being discontinued. At the same time, the probability of the good stocking out predictably rises.

\footnotetext{
5 The relevant information set in equation (4) is that available when $p_{t-1}$ is determined. For convenience, (4) assumes that price for time $t-1$ is determined at the same time (or with same information) as output for $t-1$. But the empirical work can allow for price to be determined subsequent (or prior) to output by conditioning on a broader (or narrower) set of variables.
} 
The constant expectation for $\Gamma_{t} m_{t}$ provides a way to estimate the magnitude of markups given knowledge of the rate that $\Gamma_{t}$ increases and prices decline with product life.

\section{Stockout Patterns}

\section{Stockout information from micro CPI data}

To calculate the CPI the BLS collects prices on about 90,000 non-housing goods and services per month with each price specific to a particular product at a particular outlet. About half of goods are priced monthly, with the others priced bimonthly. ${ }^{6}$ These prices, and other information related to constructing the non-housing components of the $C P I$, are contained in the BLS' CPI Commodities and Services Survey (CPI C\&S Survey). Some CPI items are sampled monthly, others only bimonthly. I aggregate the CPI data into bimonthly periods, starting with January/February 1988.

A product must be available for purchase at the outlet at the time of visit by the BLS agent in order to be included in the CPI. If the product is unavailable for sale, the BLS agent is instructed to establish if the outlet expects to carry the item in the future. This information on product availability is contained in the CPI C\&S Survey. I classify a product at an outlet as stocked out if it is not available for sale, it is continuing to be carried by the outlet, and it is not seasonally unavailable. ${ }^{7}$

I examine stockout rates using the CPI data, for January 1988 through October 2009. I examine stockout rates for more than 180 separate categories of consumer goods, as defined

\footnotetext{
${ }^{6}$ Prices are collected from about 22,000 outlets across 45 geographic areas. The BLS chooses outlets probabilistically based on household point-of-purchase surveys, and choose items within outlets based on estimates of their relative sales. The BLS divides consumption into 388 categories called Entry Level Items (ELIs). The BLS sampling methods are described in detail in Armknecht, et al. (1997) and the BLS Handbook of Methods (1997).

${ }^{7}$ The definition of available for purchase can vary across outlets. Consumers must have access to the product in the standard manner at that outlet. For instance, items typically sold from a warehouse, with only a floor model in the outlet, are considered available provided the product is available at the warehouse. Some products are unavailable to be priced because the entire outlet is not open. I do not count these as stockouts.
} 
by BLS Entry Level Items (ELIs). Slightly over half of the ELI's represent NIPA durables or apparel--I treat apparel among durables, when a distinction is drawn. I aggregate the ELI categories into 20 broader groupings to match detailed NIPA categories for consumer spending, 10 durables (including apparel) and 10 nondurable. Note that vehicles are not included in the data. Price quotes for vehicles are collected in a somewhat different manner than for most other consumer goods, which precludes observing stockout rates. ${ }^{8}$ I construct stockout rates separately for each of the 20 spending categories by appropriately weighting ELI categories within each of these categories. ${ }^{9}$ I then weight each of the twenty categories by relative expenditure shares in the CPI to get overall statistics.

Table 1 provides the number of observations and the relative importance of each category based on expenditure shares. The total number of observations for the benchmark sample is 11,568,264. Combined expenditure share for the goods (for 1997) is 26 percent. Spending on these goods is more volatile than for services (including housing services); so they represent a disproportionate share of cyclical fluctuations in consumer spending.

\section{Stockout rates}

Temporary stockouts are quite frequent, averaging 7.8 percent for my sample of goods. Studies of stockout frequencies have been largely based on supermarket data. For instance, Aguirregabiria (2003) cites a study by Anderson Consulting in 1996 showing a stockout rate of 8.2 percent across a sample of U.S. supermarkets, which is quite close to the rate reported here for the broader array of goods.

\footnotetext{
${ }^{8}$ A vehicle quote begins with a purchase invoice for a particular model at a dealer. At subsequent visits, the BLS agent inquires as to how price (incorporating discounts) have changed for that particular model. But, if that particular model had no sales at that dealership that period, then it is coded temporarily unavailable. Thus it is not possible to distinguish stockouts from zero sales.

9 The BLS selects outlets proportionally to their importance in a somewhat wider product category than an ELI, for instance, based on men's clothing, not the specific ELI men's shirts. For this reason, I weight individual observations by the percentage of sales within the broader category at the outlet corresponding to that ELI. The BLS labels this percentage as the percent of pops category.
} 
The first-order condition above assumes positive production at $t+1$. For products near the end of their product life this may not apply. The value of a stockout is lower if the firm has a better (relative to cost) substitute coming on line. For this reason, for the balance of the paper I focus on stockouts that do not closely precede a product being classified as more permanently discontinued at an outlet, excluding observations that directly precede the item being labeled as permanently or seasonally unavailable. ${ }^{10}$ I further restrict the sample to observations that are followed by further appearance of the product at an outlet. That is, to be a temporary stockout the product must come back. ${ }^{11}$ This results in an overall stockout rate of 4.6 percent.

Stockout rates vary noticeably across the goods categories. Table 1 gives rates separately for the 20 categories of goods. The lowest stockout rate is 1.6 percent for tires and vehicle parts. The highest stockout rates are 9.0 percent and 8.9 percent respectively for jewelry \& luggage and women's' apparel.

\section{Judging the Size of Markups from Product-Life Changes in Stockouts}

The first-order condition (2) relates predictable changes in stockout rates to predicted changes in the markup and intertemporal marginal cost. In the next section this relationship is used to infer the cyclical changes in price markups. Note, however, that (2) suggests that, all

\footnotetext{
10 The stockout rate is systematically much higher in the two months prior to a product becoming permanently or seasonally unavailable. The high rate of temporary stockouts within two months of the product being more permanently unavailable may be exaggerated if BLS pricing agents initially misinterpret some more permanent product stockouts as temporary stockouts. A concern in the opposite direction is that some products that are repeatedly unavailable due to temporary stockouts become classified as permanently unavailable. This is a potentially bigger concern because, if a product is repeatedly unavailable, it may trigger an instruction to the field agent to substitute a new product version for pricing at the next visit. In practice, however, it appears that the field agents often continued to price the old version, usually because the product again became available for sale. (This is based on analysis conducted by Teague Ruder.)

${ }^{11}$ In calculating stockout rates I eliminate the first observation that an item is followed because, reflecting BLS methods for selecting items in an outlet, the initial stockout rate will be zero.
} 
else equal, a one-percent $\log$ change in the markup implies an opposite one-percent $\log$ change in the stockout rate. For instance, an increase in the stockout rate from 5 percent to 6 percent would be implied by a 20 percent drop in the markup. But this drop in the markup could reflect a drop from 30 percentage points to 25, or from 6 to 5 . For discussing the impact of cyclical variations in price markups, a drop in the markup from 30 percentage points to 25 is five times as important as a drop from 6 percentage points to 5; it reflects a five-times greater drop in the implicit tax of the price-markup on turning leisure into consumption.

One can gauge the size of the markup from a reverse exercise: Given a particularsized change in price relative to marginal cost, what percent impact does this have on the probability of stocking out? The answer reflects the size of the markup. Durable goods have predictably show sharp declines in prices over the life of a product model. I examine to what extent stockout rates increase in conjunction with these predictable declines for the durable goods categories, including the three apparel categories. ${ }^{12}$

Taking unconditional expectations of the first-order condition in (3), then time differencing yields

$$
E\left(\Delta\left(\Gamma_{t} m_{t}\right)+\Delta \ln \left(\frac{\beta_{t} c_{t+1}}{c_{t}}\right)\right) \approx 0 .
$$

where $\Delta x_{t}$ denotes the time difference in variable $x_{t}$. The second term is the rate of acceleration in (discounted) marginal cost. If we assume that the rate of growth in marginal cost is constant over the product life, then this second term has expectation of zero; this

\footnotetext{
12 In principle it is possible to gauge the size of markups from the unconditional expectation in equation (2). The markup should be equal to the real interest rate for a good (defined by netting its average rate of growth in marginal cost from a nominal interest rate) divided by the stockout rate. If the interest rate is measured by the one month commercial paper rate and one assumes that the average rate of growth in marginal cost equals the average rate of price inflation for consumer durables, this implies a monthly real interest rate of 0.46 percent. Given a stockout rate of 4.6 percent, this is consistent with a markup of about 10 percent, if one assumes a monthly period for producing and shipping the good. But there are several holes in this calculation. The calculation ignores storage costs, which are difficult to measure. Secondly, the rate of inflation should be significantly lower than the rate of increase in marginal cost for a product, once it is on the market, as the rate of inflation reflects technological improvements for newer product versions. Finally, and most importantly, this calculation assumes a monthly production/shipping decision. Assuming quarterly would triple the implied markup; assuming weekly would cut it by three quarters.
} 
implies that the multiple $\Gamma_{t} m_{t}$ is expected to remain constant over the life cycle of the product model. Making this assumption and approximating $\Delta\left(\Gamma_{t} m_{t}\right)$ in terms of changes in $\Gamma_{t}, p_{t}$, and marginal cost yields

$$
E\left(m_{t} \Delta \Gamma_{t}+\Gamma_{t}\left(1+m_{t}\right)\left(\frac{\Delta p_{t}}{p_{t}}-\frac{\Delta\left(\beta_{t} c_{t+1}\right)}{\beta_{t} c_{t+1}}\right)\right) \approx 0 .
$$

I compare the average increase in stockout rate to the average rate of decrease in price relative to (a proxy for) marginal cost as a product remains for sale at a particular outlet. (5) implies the magnitude of the markup can be gauged by requiring that the rate of fall in price relative to marginal cost imply a rate of drop in the markup equal to the rate of increase in the stockout rate. For instance, if changes in markup rates are orthogonal to levels of markups and stockout rates, then (5) implies

$$
\frac{\bar{m}}{1+\bar{m}} \approx-\left(\frac{\Delta \bar{p}}{p}-\frac{\Delta(\bar{\beta} c)}{\beta c}\right) / \frac{\bar{\Delta} \Gamma}{\bar{\Gamma}} .
$$

where a bar above a variable implies its average over the product life.

Table 2, Column 1, reports the weighted average change in stockout rate and percent change in price over the 10 durable categories (including apparel). The annualized change in stockout rates is large, at 6.6 percentage points. (I annualize rates here for exposition; but recall that the data reflect bimonthly changes, so the average bimonthly change is 1.1 points.) This annualized change is equal to 110 percent of the average stockout rate for these goods of 6.0 percent. The average price change is an annualized decrease of 5.45 percent. $^{13}$

To employ equation (6) requires knowing how the markup of price over marginal cost changes with product life; so it is necessary to net the rate of growth in marginal cost from the rate of price change. A higher rate of growth in marginal cost implies a faster decline in the markup and, given the rate of increase in stockouts, a higher markup. I consider two proxies

\footnotetext{
13 A potential selection problem exists in that prices are usually not observed if the product stocks out. Since stockout rates increase as the product life ages, this selection problem grows. But, in calculating average price changes I include the price observation when the product returns from stockout (even though stockout rates are not based on the last time the product is observed.) So even if a potential price cut is not captured coincidentally with a stockout, its impact on price trends is captured when the product returns.
} 
for the rate of growth in marginal cost for a static, unchanging product. Fortunately calculated markups are not overly sensitive to that choice of proxy. For benchmark results I assume that productivity is constant as the product ages. This is consistent with established products exhibiting no technological change. The growth rate in marginal cost can then be related to inflation in input prices. I set inflation in marginal cost to the rate of inflation in the hourly wage rate for durable goods manufacturing. (The source is the BLS program on Major Sector Multifactor Productivity and Costs.) That rate averaged 3.59 percent per year from the first quarter of 1988 to the third quarter of 2009. Table 2 reports that for durable categories the average rate of change in price relative to this measure of marginal cost averaged -9.04 percent per year.

This first measure presumably overstates the rate of growth in marginal cost, as we would expect some productivity growth for products after market entry. As a second measure, I assume that static (unchanging) products exhibit one-half the trend productivity growth in a sector. I set trend productivity equal to the annual rate of growth in labor productivity for durable goods manufacturing. (Again the source is the BLS program on Major Sector Multifactor Productivity and Costs.) That rate averaged 3.85 percent per year. Subtracting half that rate from the rate of growth in wages yields trend growth in nominal marginal cost of 1.67 percent per year; it yields an annual rate of change in price relative to marginal cost of -7.11 percent.

The last row of Table 2 reports the calculated. Assuming no productivity growth for static goods, the calcuated markup is a modest 7.6 percent. If static goods exhibit one half of the labor productivity growth for durable manufacturing this reduces the markup from 7.6 to 6.1 percent.

The sharp increase in stockout rates with product life, and the small markups implied, do not reflect extreme stockout rates at the end of products' lives. The estimates are based on observations at least 3 months prior to the model disappearing and require that an item returns from stockout. Nevertheless, it is clear that stockout rates grow much more rapidly during the later stages that the product is sampled. For each item surveyed, I broke its observed sample 
period into first and second halves. Column 2 of Table 2 repeats all calculations based just on the first half of each item's sampled period. I treat these estimates in the second column as the more meaningful benchmark. The BLS draws it sample of products to be representative of consumer purchases. So, on this basis, the front of each good's sample period is more representative of consumer spending than later in its sampled period.

Focusing on Table 2, Column 2, we see that the average stockout rate is lower in the front half of products sample period, at 4.6 percent compared to 6.0 percent overall.

Furthermore, the rate of increase in stockouts is much slower in the front half, at 2.4 percentage points per year. The stockout rate increases at an annualized rate of 52 percent during the first half of the measured sample, compared to roughly twice that, 110 percent, over the entire sample life. The rate of decline in relative price, 9.3 percent per year is roughly the same as later in the sampled period. ${ }^{14}$ Thus the much slower rate of increase in stockout rate implies a considerably higher estimated markup of 15.2 percent. This is double that calculated in Column 1. Allowing for productivity growth for existing products, equal to onehalf of overall productivity growth, yields a modestly lower calculated markup of 12.5 percent. ${ }^{15}$

Table 3 presents results separately across the 10 durable categories. These results parallel those from Table 2, Column 2. That is, all calculations are based on the front half of an item's sampled period. The first column reports the average stockout rate. For all 10 categories this rate is lower than calculated over items entire sampled period, as reported in

\footnotetext{
${ }^{14}$ Note that even though I estimate that price declines at a similar rate relative to marginal cost over the first and second halves of items' samples, this still implies the markup falls at a much faster percent rate in the latter half when that markup is much smaller.

15 A simplifying assumption made here is that a stockout results in a lost sale. If we allow for a fraction of sales to be recouped at the posted price, the analysis carries through. Even though the stockout rate exaggerates the frequency of lost sales, the rate of change in the stockout rate still captures the rate of change in lost sales. Alternatively, suppose that consumers make multiple searches. An effective stockout corresponds not to the event of a stockout at one retailer, but when a consumer stops searching for the product. Note, however, that this suggests that effective stockout rates responds even more to changes in markups. As an illustration, suppose that consumers are willing to search two time for the product and that stockout probabilities are independent across these searches. Then the probability of an effective stockout would be measured by the outlet rate squared. This implies the percent change in effective stockout rates would be double what I have reported. In terms of equation (6), this would cut the calculated markup by half.
} 
Table 1. Column 2 reports the annualized rate of change in the stockout rate. The stockout rate increases for all categories except furniture. For furniture the stockout rate declines slightly over the front half of the sample period, though it does increase over the later stages that a product is sampled. The rate of increase in the stockout rate is particularly rapid for women's' apparel and for footwear. Column 3 reports the annualized change in nominal price, relative to the durable manufacturing wage, as the product ages. That relative price falls notably for all 10 categories, but especially for women's apparel, footwear, and electronics.

Markups calculated separately by category appear in the final column of Table 3. For the most part the markups are reasonably low. Exceptions are household appliances, which yield a markup of 55 percent, and electronics and women's' apparel, each of which yield a markup of about 22 percent. No markup is calculated for furniture, as the decline in stockout rate, together with a fall in price relative to marginal cost, is not consistent with a positive markup. ${ }^{16}$ The overall average markup, weighting by each category's expenditure share and excluding furniture, equals 16.9 percent.

These calculations take the sharp rise in stockout rates over the product life as evidence against high markups. The related point is that, based on the product life, stockouts appear quite responsive to markup changes. So, if markups vary importantly with the business cycle, we can anticipate seeing opposite, predictable movements in stockouts.

\section{Cyclical Fluctuations in Stockouts}

Figure 1 graphs bimonthly stockout rates, combining all categories, for March/April 1988 to July/August 2009. The stockout rate is seasonally adjusted. ${ }^{17}$ NBER-defined

\footnotetext{
16 If we use the entire measured sample for furniture price quotes, there is a rise in stockout rates, implying a modest markup of 3.2 percent.

17 Categories are aggregated by time period, weighting categories by CPI expenditure shares. As before, stockout statistics statitics exclude observations directly prior the product being seasonally or permanently unavailable, and require a subsequent availability of the item.
} 
recession are shaded. The figure also plots the comparable stockout rate just for the 10 durable categories, including apparel. These categories are of special interest, given expenditures are much more cyclical for durable consumer goods. Figure 1 shows a clear increase in stockout rates over the first sixteen or so years of the sample period. For all categories the stockout rates climbs from about 3.5 percent to 5.5 percent; for durable categories the climb is even sharper, from about 4 percent to 7 percent. After that, however, the stockout rates levels off or decline.

To examine cyclicality, I first remove a Hodrick-Prescott trend from stockout rates. (The HP-filter parameter is 3600.) I then relate cyclical stockout rates to cyclical movements in total hours in manufacturing for non-supervisory workers. I measure the cycle by labor hours because hours are available from the BLS Current Employment Survey monthly. I restrict attention to manufacturing, as stockouts are only measured for goods, not services. ${ }^{18}$ The first-order condition, equation 3, describes the expectation of the markup times the stockout rate in $t$, conditional on information available when choosing the stock available for sale in $t$. Hours choices during bimonthly period $t$ could reflect reactions to stockouts that occur earlier in that bimonth. For this reason, I instrument for manufacturing hours with manufacturing hours lagged one bimonthly period; these predated hours are presumably in the time $t$ information set. ${ }^{19}$

Table 4, Column 1, Row 1, reports the results from regressing the stockout rate on (instrumented) manufacturing hours for all 20 goods categories for March/April 1988 to July/Aug 2009. The sample period includes three NBER-defined recessions, as it ends just past the NBER trough for the Great Recession (June 2009). The estimated relationship is positive. A one percent increase in hours increases the stockout rate by 0.20 percentage

\footnotetext{
18 Total hours equals employment times average hours per week. The measure is restricted to non-supervisory workers, as the workweek is only available for these workers back to 1988 . Nonsupervisory workers constituted about 73 percent of all employees for manufacturing during the sample period. Total hours are logged, seasonally adjusted, and HP filtered.

19 The first-stage regression yields a coefficient of 0.92 (standard error of 0.03 ) and an R-squared of 0.80 .
} 
points; that represents a 4.3 percent increase relative to the average stockout rate of 4.6 percentage points. But this estimated effect is not statistically different from zero.

Figure 2 plots the HP-filtered stockout rate and hours. For much of the sample period stockouts show little cyclical relationship--in particular they neither track with or opposite the decline in hours circa the shaded recessions for 1992 and 2001. But, the stockout rate does largely track hours in the latter part of the sample, most notably dropping nearly a full percentage point as hours fell during the great recession. (Notice neither hours or the stockout rate declined until part way into 2008.) That constitutes about a 20 percent decline in the stockout rate compared to its mean. Under a scenario of a constant real interest rate, that would imply a 20 percent increase in markups, such as going from 15 percentage points to 18 percentage points. The shift in markup cyclicality is displayed in regressions reported in the last two rows of Table 4, Column 1. Here I break the sample, somewhat arbitrarily, before and after the beginning of 2005. Through 2004 the stockout rate is acyclical. But from 2005 forward it is highly cyclical, both statistically and economically, with a one percent decrease in hours associated with a half percentage point decrease in the stockout rate.

Column 2 of Table 4 repeats the regressions for just the 10 durable categories. For these more cyclical goods the same message applies, but only amplified. Prior to 2005 the stockout rate is acyclical. But for 2005 forward it is strongly procyclical. A percent decrease in hours is associated with a 0.82 percentage point decrease in the stockout rate. That represents about a 14 percent decline relative to its mean. In fact, this end of sample cyclicality is sufficiently strong to make the stockout rate marginally statistically procyclical over the entire 1988 to 2009 sample (Row 1 of Column 2).

Recall from first-order condition (3), repeated here, that predictable

$$
E\left(\Gamma_{t} m_{t}+\ln \left(\frac{\beta_{t} c_{t+1}}{c_{t}}\right) \mid \boldsymbol{I}_{t}\right)+\kappa \approx 0 .
$$

variations in stockouts can be related to the markup and/or intertemporal movements in marginal costs. The discussion of cyclicality to this point has implicitly acted as though expected movements in $\ln \left(\frac{\beta_{t} c_{t+1}}{c_{t}}\right)$ are orthogonal to the measure of the business cycle. 
Measuring cyclical movements in marginal cost are complicated by the fact that we do not have data on marginal cost. As a partial answer, here I consider the cyclical behavior of $\ln \left(\frac{\beta_{t} c_{t+1}}{c_{t}}\right)$ under the strong assumption that the markup is literally constant. Under that assumption $\ln \left(\frac{\beta_{t} c_{t+1}}{c_{t}}\right)$ can be measured by $\ln \left(\frac{\beta_{t-1} p_{t}}{p_{t-1}}\right) . \ln \left(\frac{\beta_{t-1} p_{t}}{p_{t-1}}\right)$ is simply the negative of the good's own-price real interest rate, $-\ln \left(\frac{1 / \beta_{t-1}}{p_{t} / p_{t-1}}\right)$, where own-price real interest rate equals the nominal interest rate minus inflation in the good's price. If that real interest rate is cyclical, that should act to push the stockout rate in that same cyclical direction, in addition to any impact from cyclicality in the markup. ${ }^{20}$

I examine cyclicality in the own-good real interest rate for the 20 goods categories. The nominal interest rate is measured by the one-month commercial paper rate (source is the Federal Reserve Board). The rate of inflation is that in the PCE deflator for the 20 categories. $^{21}$ Both these series are monthly. I convert them to bimonthly for comparability with the stockout data. The real interest rate is expressed in monthly terms. This is the right magnitude if production/shipping decisions are made monthly. The real interest rate relevant for period $t$ stockouts in equation (3) is lagged by one decision period. It is not clear, however, that a decision period is as long as the bimonthly periodicity of the data. For this reason, I report cyclicality relating the bimonthly ex post real interest rate to (instrumented) manufacturing hours in the same bimonthly period. But results are very similar if I lag the real interest rate by a bimonth.

Results for real interest cyclicality for all 20 categories (Column 1) and for the 10 durable categories (Column 2) are displayed in Table 5. For 1988 to 2009 the real interest rate is acyclical. But this masks a significantly procyclical real interest rate for the first 17 years of the sample, as shown in Row 2 of the table. By contrast, during the more cyclical

\footnotetext{
20 Bils and Kahn (2000) make additional assumptions in order to provide joint estimates of the cyclicality of $m_{t}$ and $\ln \left(\frac{\beta_{t} c_{t+1}}{c_{t}}\right)$.

21 I take PCE inflation for all goods, then subtract that in vehicles, energy, and prescription drugs, weighted by relative 1997 expenditure shares, as these goods are not reflected in my categories. of goods. Similarly, for the durable categories, I start from the inflation rate for durables, subtract that for vehicles, and add that for apparel. The source for inflation rates is the BEA NIPA Underlying Detail Table 2.4.4U.
} 
latter part of the sample (years 2005 and after) the real interest rate was, if anything, countercyclical. These patterns definitely do not help in explain why stockout rates became more procyclical in the latter part of the sample. The shift to a less procyclical real interest rate should have acted to create a less procyclical stockout rate.

To illustrate this last point, consider again the expectation in equation (3). Under a constant markup this implies that the combination $\Theta_{t}=\Gamma_{t} m+\ln \left(\frac{\beta_{t-1} p_{t}}{p_{t-1}}\right)$ should have a constant expectation. (Again, the latter term is just the negative of a good's own real interest rate.) As a test of a cyclically constant markup, Table 6 reports results of regressing $\Theta_{t}$ on (instrumented) manufacturing hours. I construct $\Theta_{t}$ assuming a constant markup of 15 percent, consistent with results in Section 4. But results here are not sensitive to reasonable alternatives. Results for the whole sample period (Row 1) show no cyclicality in $\Theta_{t}$, consistent with an acyclical markup. But Rows 2 and 3 show, respectively, a countercyclical $\Theta_{t}$ for 1988 to 2004 and a procyclical $\Theta_{t}$ for 2005-2009. This cyclicality is economically significant; it is highly statistically significant for 1988 to 2004, somewhat so for the latter period. The cyclicality in $\Theta_{t}$ rejects the null assumption of a constant markup. The natural alternative is that the markup was procyclical over the 1988 to 2004 period, while countercyclical during the volatile 2005-2009 period.

\section{Conclusions}

Price markups over marginal cost are difficult to estimate because marginal cost is not measured absent key assumptions. This difficulty is exacerbated for cyclical variations in marginal cost because marginal adjustment costs and distinctions between the allocative versus average wage rate are likely to have important cyclical movements that are especially difficult to measure. In a simple model of producing to stock, with a stockout constraint, stockouts bear a clear relationship to the price markup because the cost to a seller of stocking 
out is the loss of the markup over marginal cost. For this reason, I exploit the behavior of stockouts to measure the size of the markup and to gauge its cyclicality.

I find that the rate of increase in stockouts over the product life for durable goods, including apparel, requires markups on the order of 15 percent. Several papers (e.g., Morrison, 1992, Norrbin, 1993, Basu and Fernald, 1997) estimate markups in the range of 5 to 15 percent based on examining productivity patterns or estimating cost functions. So my results are at the upper end of that range. (Hall, 1988, finds much larger markups, on the order of 100 percent, based on estimating the responses of output to instrumented expansions in inputs.)

I find that stockouts were acyclical for the first 17 years of my sample, 1988 to 2004. This suggests markups that were acyclical, or even procyclical given that real interest rates for my goods were procyclical during that period. This runs counter explanations for the strong cyclicality of employment based on countercyclical price markups, including Keynesian sticky-price models. Stockout behavior for 1988 to 2004 also contradicts findings by Bils and Kahn (2000) and Kryryvtsov and Midrigan (2012) that countercyclical markups are required to explain the persistent countercyclical behavior of inventory-sales ratios in a number of industries. Those papers consider an earlier time period and a differing set of goods from those considered here. But it is surprising that cyclicality of stockouts do not mirror (inversely) the strong countercyclicality in inventory sales ratios seen for nearly all industries. One possibility is that strong increasing returns in holding inventories implies that an increase in sales requires little increase in inventories to maintain the same probability of stocking out. Another possibility would be much greater uncertainty in sales, relative to the level of sales, in recessions than booms, as this requires greater inventories relative to sales to maintain the same stockout rate.

By contrast, stockouts are quite procyclical, consistent with countercyclical markups, for the latter part of my sample. In particular, stockouts declined by nearly a full percentage point during the Great Recession, equal to about 20 percent of the average stockout rate. If real interest rates were acyclical, that would suggest a 20 percent increase in markups, such as 
from 15 to 18 percentage points. In fact, real interest rates became procyclical during the latter part of the sample, suggesting that markups were even more countercyclical than this calculation during the period of the Great Recession.

The finding that stockouts were procyclical, and implied markups countercyclical, when real interest rates were most countercyclical perhaps lends support to models that link pricing to firms's borrowing costs and constraints. An important recent example is Gilchrist, Schoenle, Sim, and Zakrajsek (2014). They find that financially-constrained firms chose higher prices during the Great Recession. They interpret this within a customer market model, where firms move to higher markups, rather than investing in market share, if borrowing costs increase. But any model where expanding production has a component of investment (e.g., learning-by-doing) should have similar implications for how output and price markups respond to increased borrowing costs. 


\section{References}

Aguirregabiria, Victor (2003), "Strategic Stockouts in Supermarkets," manuscript, Boston University.

Basu, Susanto and John Fernald, (1997), "Returns to Scale in U.S. Manufacturing: Estimates and Implications," Journal of Political Economy 105, 249-283.

Basu, Susanto and Christopher L. House (2015), “Challenges for New Keynesian Models with Sticky Wages,” manuscript.

Bils, Mark (1987), "The Cyclical Behavior of Marginal Cost and Price," American Economic Review 77, 838-855.

Bils, Mark and James A. Kahn (2000), "What Inventory Behavior Tells Us about Business Cycles?" American Economic Review 90, 458-481.

Bils, Mark, Peter J. Klenow, and Benjamin Malin (2015), "Resurrecting the Role of the Product Market Wedge in Recessions, manuscript.

Campo, K., E. Gijsbrechts, and P. Nisol (2003), "The Impact of Retailer Stockouts on Whether, How Much, and What to Buy," International Journal of Research in Marketing 20, 273-286.

Emmelhainz, M., J. Stock, and L. Emmelhainz (1991), "Consumer Responses to Retail Stockouts," Journal of Retailing 67, 138-147.

Fitzsimons, G. (2000), "Consumer Response to Stockouts," Journal of Consumer Research 27, 249266.

Galeotti, Marzio, Louis J. Maccini, and Fabio Schiantarelli (2005), "Inventories, Employment, and Hours," Journal of Monetary Economics, 52,575-600..

Gali, Jordi, Mark Gertler, J. David Lopez-Salido (2007), "Markups, Gaps, and the Welfare Costs of Business Cycle Fluctuations," Review of Economics and Statistics, 2007, 89, 44-59.

Gilchrist, Simon, Raphael Schoenle, Jae Sim, and Egon Zakrajsek (2014), "Inflation Dynamics During the Financial Crisis,” manuscript.

Goodfriend, Marvin and Robert G. King (1997), "The New Keynsian Neoclassical Synthesis and the Role of Monetary Policy," NBER Macroeconomics Annual 12, 233-283.

Hall, Robert E. (1988), "The Relation Behind Price and Marginal Cost in U.S. Industry," Journal of Political Economy, 96, 921-947.

Hall, Robert E. (2014), "What the Cyclical Behavior of Advertising Reveals About Markups and Cyclical Wedges," manuscript. 
Hansen, Lars Peter and Kenneth J. Singleton (1982), "Generalized Instrumental Estimation of Nonlinear Rational Expectations Models," Econometrica, 50, 1269-1286.

Kahn, James A. (1987), “Inventories and the Volatility of Production.” American Economic Review, 77, 667-79.

Kahn, James A. (1992), "Why is Production more Volatile than Sales? Theory and Evidence on the Stockout-Avoidance Motive for Inventory Holding.” Quarterly Journal of Economics, 107, 481510.

Kudlyak, Marianna (2014), “The Cyclicality of the User Cost of Labor,” Journal of Monetary Economics, 68, 53-67.

Karabarbounis, Loukas (2014), “The Labor Wedge: MRS vs. MPN,” Review of Economic Dynamics, 17, 206 - 223.

Kryryvtsov, Oleksiy and Virgiliu Midrigan (2012), "Inventories, Markups, and Real Rigidities in Menu Cost Models,” Review of Economic Studies, 80, 249-276.

Morrison, Catherine J. (1992), "Markups in U.S. and Japanese Manufacturing: A Short-run Econometric Approach," Journal of Business and Economic Statistics, 10, 51-63.

Nekarda, Christopher J. and Valerie A. Ramey (2013), “The Cyclical Behavior of the Price-Cost Markup,” NBER WP 19099.

Norrbin, S., (1993), "The Relation Between Price and Marginal Cost in U.S. Industry: A Contradiction," Journal of Political Economy, 101, 1149-1164.

Rotemberg, Julio J. and Michael Woodford (1999), "The Cyclical Behavior of Prices and Costs." In Handbook of Macroeconomics, North-Holland: Elsevier Science Publishers B.V., North Holland Press.

Sbordone, Argia, M. (2001), "An Optimizing Model of Wage and Price Dynamics," manuscript, Rutgers University.

Shimer, Robert (2009), "Convergence in Macroeconomics: The Wedge," American Economic Journal: Macroeconomics, 1, 280-97.

Thurlow, Peter H. (1993), Essays on the Macroeconomic Implications of Inventory Behavior. Ph.D. dissertation, University of Toronto.

U.S. Department of Labor (1997), BLS Handbook of Methods, Bulletin 2490, U.S. Government Printing Office. 
Table 1: Stockout Rates by Good

\begin{tabular}{cccc|}
\hline NIPA Good & $\begin{array}{c}\text { Observations } \\
\text { (in 1000's) }\end{array}$ & $\begin{array}{c}\text { Relative } \\
\text { Importance } \\
\mathbf{( \% )}\end{array}$ & $\begin{array}{c}\text { Stockout } \\
\text { rate } \\
\mathbf{( \% )}\end{array}$ \\
Tires \& vehicle parts & & 1.9 & 1.6 \\
Furniture & 204.9 & 4.7 & 3.7 \\
Household appliances & 144.8 & 1.9 & 4.9 \\
Video, audio, computer equip. \& accessories & 98.2 & 4.7 & 5.8 \\
Tableware, hardware, flooring, indoor \& outdoor equip. & 181.1 & 4.9 & 4.7 \\
Books, sporting goods, photo \& musical equip. & 271.4 & 4.9 & 5.4 \\
Jewelry, watches, luggage & 267.2 & 2.0 & 9.0 \\
Women \&girls' apparel & 137.4 & 8.8 & 8.9 \\
Men, boys, \& infants' apparel & 408.7 & 5.8 & 5.8 \\
Footwear & 457.9 & 3.6 & 5.8 \\
Cereals, baked goods, sugars, sweets, oils & 219.0 & 7.9 & 2.7 \\
Meats, poultry, fish & 1540.7 & 9.2 & 4.3 \\
Milk, eggs, fresh fruit \& vegetables & 2317.2 & 6.4 & 4.0 \\
Beverages, processed dairy, fruit \& vegetables & 2155.7 & 7.2 & 3.0 \\
Other processed foods \& pet foods & 1353.9 & 6.3 & 4.0 \\
Alcohol \& tobacco & 772.1 & 6.2 & 1.6 \\
Personal care products, nonprescription medical & 375.1 & 4.7 & 3.4 \\
Linens, indoor plants, outdoor supplies & 126.8 & 2.4 & 7.3 \\
Household cleaning \& paper supplies & 217.7 & 4.3 & 3.5 \\
Toys \& games, film, pets, pet supplies & 87.8 & 2.3 & 6.7 \\
All & & & \\
& $\mathbf{1 1 , 5 6 8 . 2 6 4}$ & $\mathbf{1 0 0 *}$ & $\mathbf{4 . 6}$ \\
\hline
\end{tabular}

Data: CPI Commodities and Services Survey. Goods account for 26 percent of overall CPI for 1997. 
Table 2: Shelf-life Changes in Stockout Rates and Prices, With Implied Markups

\begin{tabular}{|c|c|c|}
\hline & $\begin{array}{l}\text { Over Product's } \\
\text { Whole Sample }\end{array}$ & $\begin{array}{l}\text { Over 1st Half of } \\
\text { Product's Sample }\end{array}$ \\
\hline Average stockout rate & 5.95 & 4.61 \\
\hline $\begin{array}{l}\text { Annualized change } \\
\text { in stockout rate }\end{array}$ & 6.56 & 2.40 \\
\hline $\begin{array}{l}\text { Annualized percent change } \\
\text { in stockout rate }\end{array}$ & $110.3 \%$ & $52.1 \%$ \\
\hline $\begin{array}{l}\text { Annualized rate of } \\
\text { nominal change in price }\end{array}$ & -5.45 & -5.75 \\
\hline $\begin{array}{c}\text { Annualized rate of } \\
\text { change in relative price }\end{array}$ & -9.04 & -9.34 \\
\hline Implied Markup $^{\mp}$ & $7.6 \%$ & $15.2 \%$ \\
\hline
\end{tabular}

Data: CPI Commodities and Services Survey.

${ }^{\mathrm{T}}$ The relative price change and markup assume no productivity growth for static goods. If, instead, productivity growth equals half that in durable manufacturing, the markups become $6.1 \%$ and $12.5 \%$ respectively for columns 1 and 2 . 
Table 3: Changes in Stockout Rates, Prices and Implied Markups

\begin{tabular}{|c|c|c|c|c|}
\hline NIPA Good & $\begin{array}{c}\text { Stockout } \\
\text { Rate }\end{array}$ & $\begin{array}{c}\Delta \\
\text { Stockout }_{\text {Rate }^{T}}\end{array}$ & $\begin{array}{c}\text { Relative } \\
\text { price } \\
\text { change }^{\text {Th }}\end{array}$ & $\begin{array}{c}\text { Implied } \\
\text { Mark Up }^{\mp}\end{array}$ \\
\hline Tires \& vehicle parts & 0.97 & 0.33 & -2.67 & 7.3 \\
\hline Furniture & 2.91 & -0.47 & -3.54 & $\mathrm{X}$ \\
\hline Household appliances & 3.81 & 0.14 & -4.61 & 55.5 \\
\hline Video, audio, computer equip. $\&$ accessories & 4.08 & 1.27 & -9.05 & 22.5 \\
\hline Tableware, hardware, flooring, in \& outdoor eq & 3.69 & 1.26 & -4.82 & 12.4 \\
\hline Books, sporting goods, photo \& musical eq. & 4.16 & 1.88 & -3.85 & 7.9 \\
\hline Jewelry, watches, luggage & 8.00 & 4.06 & -5.17 & 9.2 \\
\hline Women \&girls' apparel & 6.80 & 5.22 & -21.84 & 22.2 \\
\hline Men, boys, \& infants' apparel & 4.61 & 2.32 & -7.49 & 12.9 \\
\hline Footwear & 4.49 & 4.56 & -11.63 & 10.3 \\
\hline All & 4.61 & 2.40 & -9.34 & $\mathbf{X}$ \\
\hline All Excluding Furniture & 4.82 & 2.75 & -10.05 & 16.9 \\
\hline
\end{tabular}

Data: CPI Commodities and Services Survey. Calculations in this table reflect an item's first half of sampled period.

${ }^{\Phi}$ The change in stockout rate and relative price change are both annualized. The relative price change and markup assume no productivity growth for static goods. 
Table 4: Cyclicality of Stockout Rates with respect to Manufacturing Hours

\begin{tabular}{|c|c|c|}
\hline & \multicolumn{2}{|c|}{$\underline{\text { Categories Included }}$} \\
\hline Time Period & All 20 & 10 Durable \\
\hline 1988 to 2009 & $\begin{array}{c}0.20 \\
(0.17)\end{array}$ & $\begin{array}{c}0.40 \\
(0.24)\end{array}$ \\
\hline 1988 to 2004 & $\begin{array}{l}-0.07 \\
(0.26)\end{array}$ & $\begin{array}{c}0.04 \\
(0.33)\end{array}$ \\
\hline 2005 to 2009 & $\begin{array}{c}0.51 \\
(0.18)\end{array}$ & $\begin{array}{c}0.82 \\
(0.25)\end{array}$ \\
\hline
\end{tabular}

Dependent variable is the stockout rate. The cyclical measure is bimonthly total hours in manufacturing (logged). All variables are seasonally adjusted and HP filtered (parameter 3600). 1988 to 2009 is, more exactly, March/April 1988 to July/Aug 2009 (129 observations); 1988 to 2004 is March/April 1988 to Nov/Dec 2004 (101 observations); 2005 to 2009 is Jan/Feb 2005 to July/Aug 2009 (28 observations). Manufacturing hours are instrumented by hours lagged one bimonthly period. In parentheses are NeweyWest robust standard errors. 
Table 5: Cyclicality of Real Interest Rate, at Monthly Rate, with respect to Manufacturing Hours

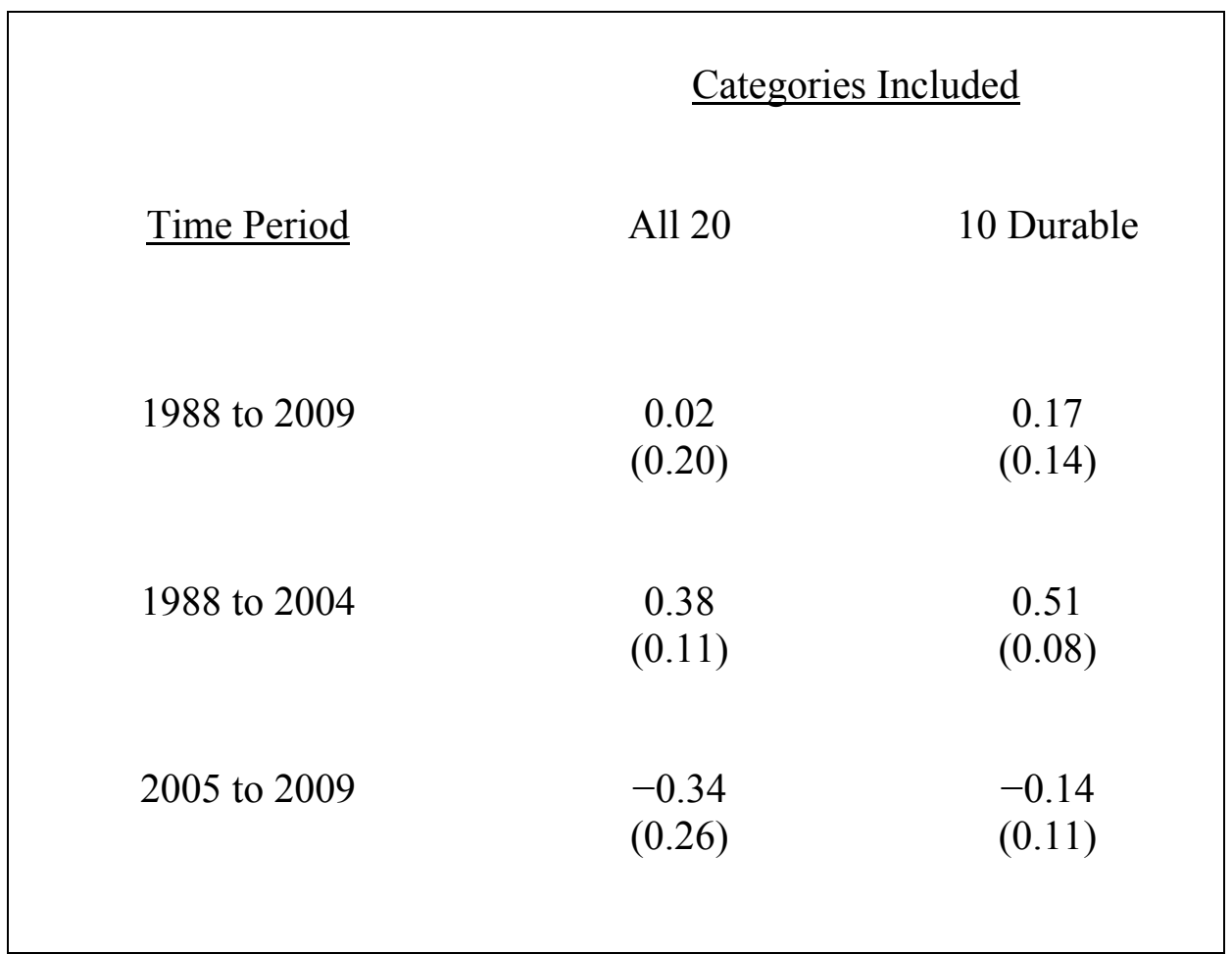

Dependent variable is the commercial paper rate minus realized inflation rate, expressed at a monthly rate. The cyclical measure is bimonthly total hours in manufacturing (logged). All variables are seasonally adjusted and HP filtered. Manufacturing hours are instrumented by hours lagged one bimonthly period. In parentheses are Newey-West robust standard errors. 
Table 6: Test of Constant Markup:

Cyclicality of $\Theta_{t}$ with respect to Manufacturing Hours

$\left(\Theta_{t}=\right.$ Markup•Stockout Rate - Real Interest Rate $)$

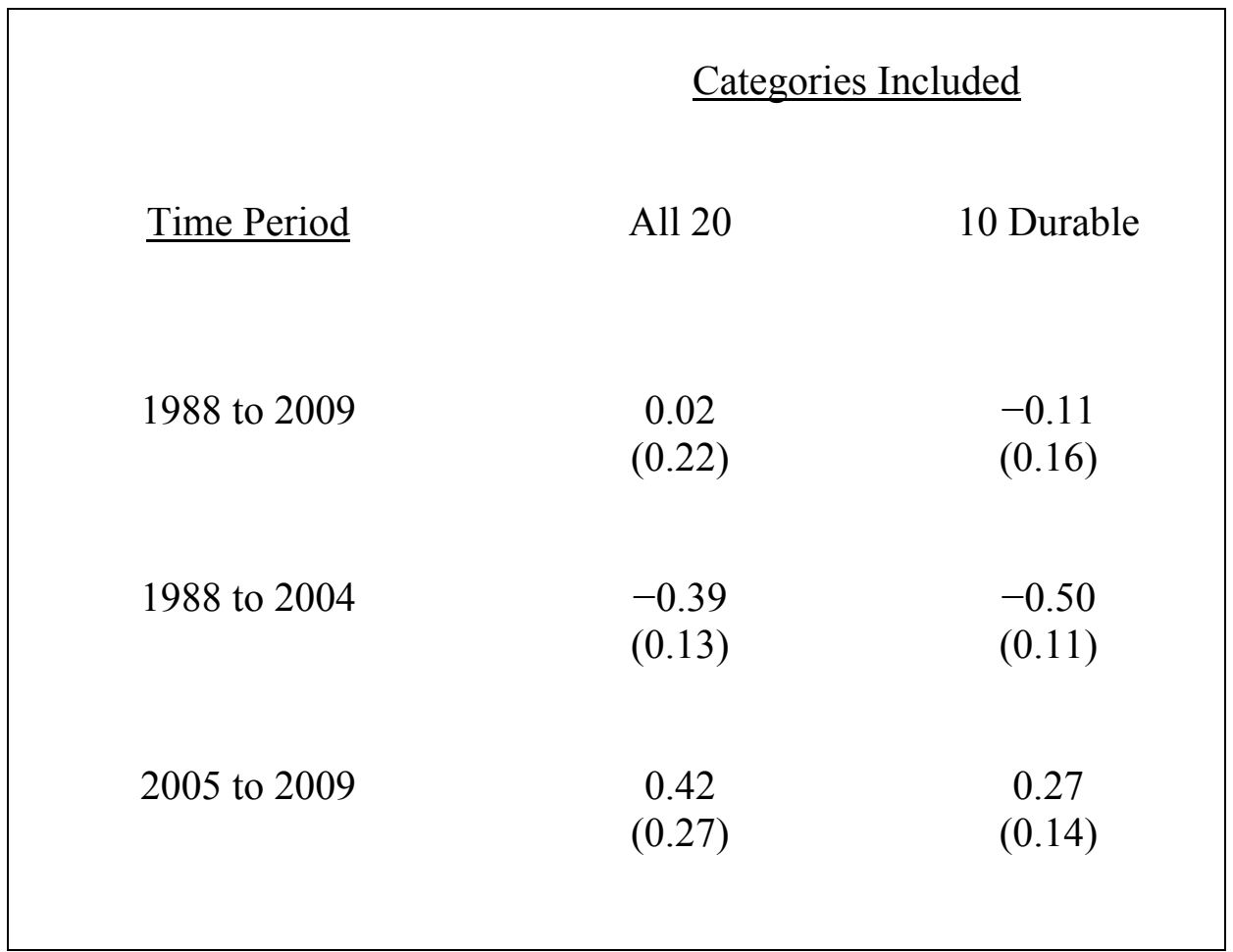

Dependent variable is $0.15^{*}$ (stockout rate) minus the real interest rate. The real interest rate equals the commercial paper rate minus realized inflation rate, expressed at a monthly rate. The cyclical measure is bimonthly total hours in manufacturing (logged). All variables are seasonally adjusted and HP filtered. Manufacturing hours are instrumented by hours lagged one bimonthly period. In parentheses are NeweyWest robust standard errors. 
Figure 1: Stockout Rates

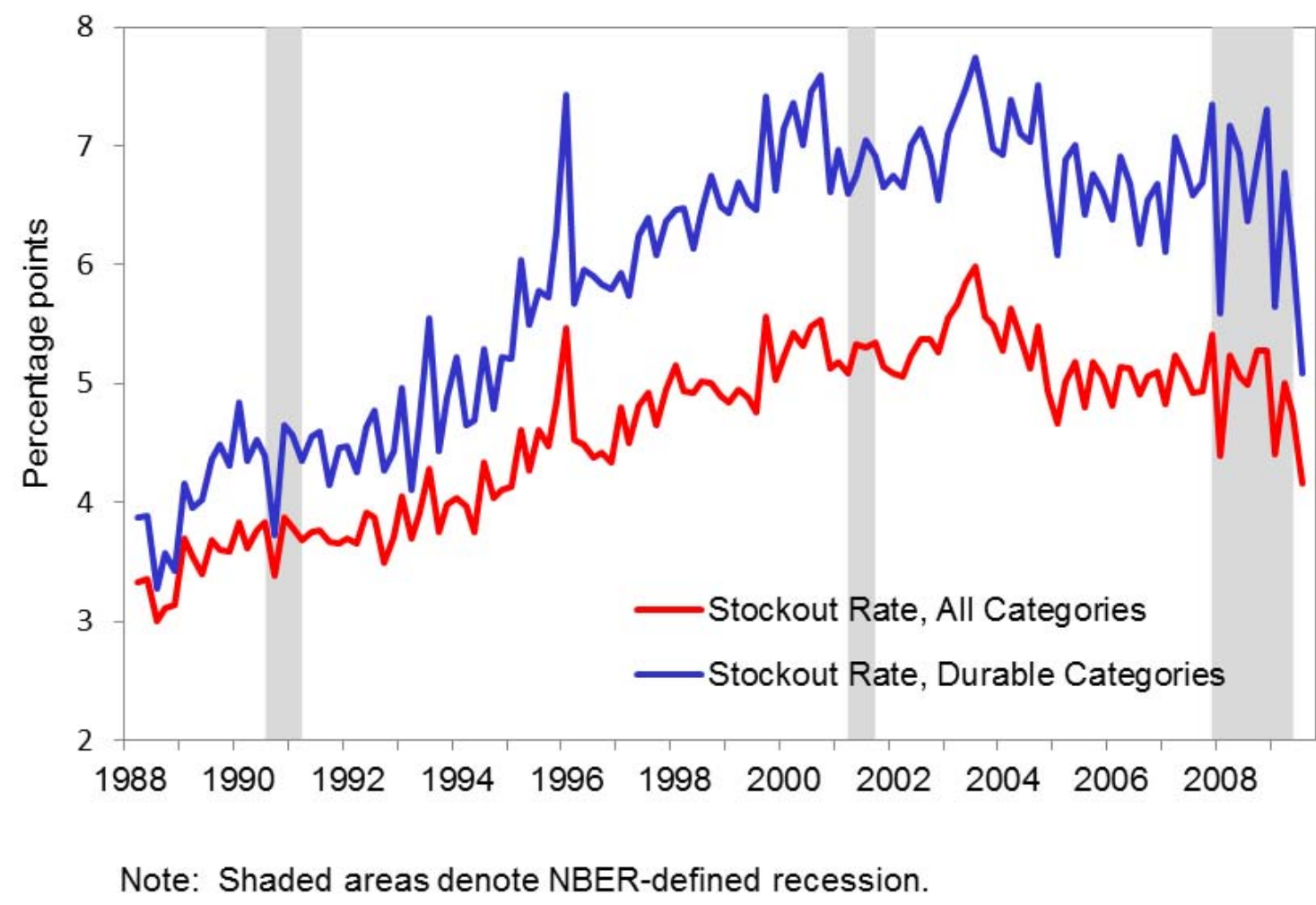


Figure 2: Stockout Rates vs Manufacturing Hours

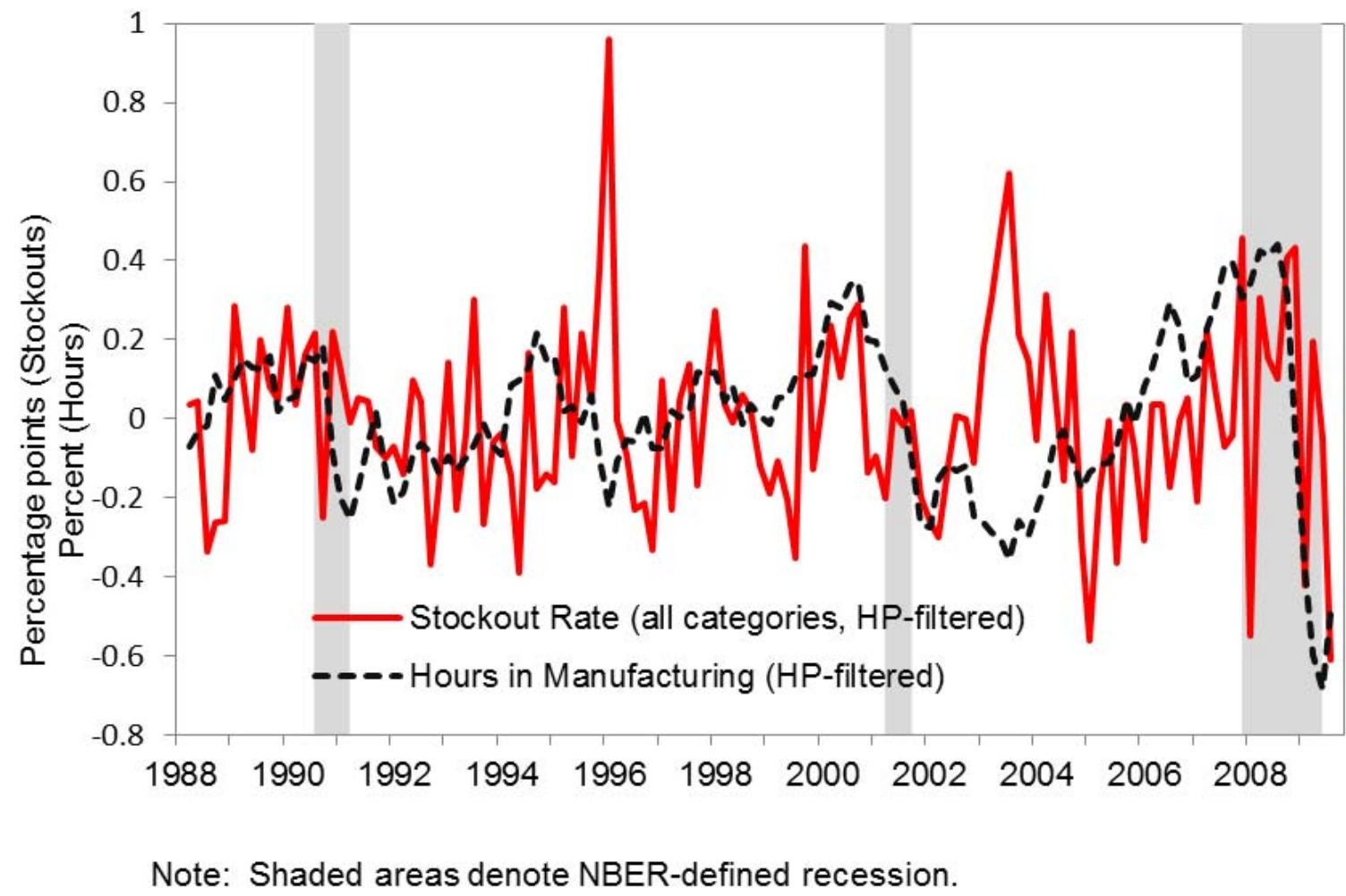

